Acta Theriologica 37 (4): 381 - 396, 1992.

PL ISSN $0001-7051$

\title{
Craniometrical sex determination of wild cat Felis silvestris in Bulgaria
}

\author{
Ivan PETROV, Hristo NIKOLOV and Svetoslav GERASIMOV
}

\begin{abstract}
Petrov I., Nikolov H. and Gerasimov S. 1992. Craniometrical sex determination of wild cat Felis silvestris in Bulgaria. Acta theriol. 37: 381 - 396.

Analyses were made of 118 skull measurements of adult wild cats Felis silvestris Schreber, 1777 from Bulgaria, taken on 24 males, 20 females, and 10 animals whose sex was not known in advance. Group (cluster) analysis of cases, factor analysis, and stepvise discriminant analysis were adapted. The cluster analysis of cases indicated a high level of sex mixture (up to $40 \%$ ), which suggested the importance of the outliers in the data. Six keys to sexual dimorphism, of very high statistical significance were produced, through the stepvise discriminant analysis. They included from 9 down to 1 variables each, which provided from $100 \%$ down to $93.8 \%$ of correct sex classification
\end{abstract} of wild cat skulls.

Forest Research Institute, 132 St. Kl. Ohridski str., 1756 Sofia, Bulgaria (IP); Institute of Zoology, 1 Tsar Osvoboditel boul., 1000 Sofia, Bulgaria (HN, SG)

Key words: Felis silvestris, sexual dimorphism, discriminant keys, Bulgaria

\section{Introduction}

Sexual dimorphism of the cranial features of wild cat Felis silvestris Schreber, 1777 was noted by French et al. (1988). Arrighi and Salotti (1988) found for wild cats from Corse a male bigger than a female. Petrov et al. (1990) noted significant differences between males and females for a population of wild cats from Bulgaria for most of 121 skull measurements. This forms a basis to apply discriminant analysis for obtaining keys to the sexual dimorphism in wild cat. Similar approach was used for Martes foina and M. martes by Gerasimov (1985). Principal component analysis (PCA) could be applied in order to determine the main sources of the morphometric differences between sexes. Both discriminant analysis (although without providing keys to classify new individuals) and PCA were applied to study sexual dimorphism in two populations of domestic cats (Wetzel et al. 1982, Petrov et al. 1992).

The aim of this study was to analyse the sexual dimorphism in skulls of wild cats in Bulgaria, using the above mentioned methods. 


\section{Material and methods}

For the study was used 24 males and 20 females of adult wild cats, Felis silvestris Schreber, 1777, from Bulgaria. Additional 10 individuals of unknown sex were used for some verifications. The material examined is kept at the National Museum of Natural History, Sofia, at the Forest Research Institute, and in some private collections.

All the material used was collected as "wild cat", and additionally, was verified by means of the Schauenberg's index (Schauenberg 1969). The values of the index were 2.46, SD $=0.134$ for males and $2.45, \mathrm{SD}=0.129$ for females.

The age of wild cats was determined by analysing annual growth layers in dentine of lower canines. The teeth were decalcified in $6.5 \% \mathrm{HNO}_{3}$ solution, cross-sectioned to $10 \mu \mathrm{m}$. Four slides were obtained for each specimen: one of them was kept unstained while each one of the other three were then stained with either of Ehrlich's, or Mayer's, or Delafield's hematoxylin. Annual growth layers were observed and counted under a microscope. The wild cats used were from $1+$ to 7 years old.

Results from PCA by French et al. (1988) showed that increasing the number of variables used increased to a greater extent the distance between sexes for old wild cats (from 3.2 to 7.1 ) than for recent and modern ones (from 2.6 to 5.7). Thus, a wide set of measures to be applied for studies of sexual dimorphism in wild cat could be recommended.

The list of all 118 skull measurements and their determinations used are given in the Appendix 1. Variables were denoted further in the text as V1, V2, etc. The scheme of measurements was the same as in Petrov et al. (1990), except V10, V53, and V81. All measurements, except the neurocranium capacity (V56), were taken by a vernier caliper, with an approximation of $0.1 \mathrm{~mm}$. The brain volume (V56) was measured using lead balls of $1.5 \mathrm{~mm}$ diameter. All measurements were taken by the same person. Locations of measurement points on wild cat skull are shown in Appendix 1.

The multivariate methods applied could be specified as follows: cluster analysis of cases based on Euclidean distances (without standardization of data prior to the analysis), principal component analysis (PCA) based on correlation matrices (with standardization of the variables used), and stepwise discriminant analysis with a choice of F-to-enter value of 4.0 (see Forsythe's remark in Dixon 1981 , pp. 698 - 699).

The statistical analysis was performed using BMDP software (Dixon 1981): BMDPKM for cluster analysis of cases, BMDP4M for PCA analysis, BMDP7M for stepwise discriminant analysis, and BMDPAM was applied for a preliminary testing of the assumptions of the above mentioned multivariate methods.

\section{Results}

The arithmetical means, and standard deviations of 118 skull measurements of wild cat from Bulgaria are listed in an Appendix 2. Multivariate analyses were utilized in order to distinguish between sexes on the basis of the whole complex of variables, and not on single variables, as it was in all univariate analyses (Petrov et al. 1990).

Cluster analysis of cases was applied on the whole data matrix not giving $a$ priori any information about sex. Although the two groups (clusters) were formed predominantly by individuals of the same sex (Table 1 ), it should be noted that about $40 \%$ of the males belonged to the "female" cluster. Thus, despite of the large number of highly significant differences that were previously found between the means of 121 dimensions for the two sexes (Petrov et al. 1990), outliers in the data seem to be important in the morphometrical characteristics of the wild cat 
Table 1. Percentages of individuals of Felis silvestris forming two clusters based on cranial or mandibular measurements.

\begin{tabular}{lccccc}
\hline \multirow{2}{*}{ Sex } & \multicolumn{2}{c}{ Cranial measurements } & & \multicolumn{2}{c}{ Mandibular measurements } \\
\cline { 2 - 3 } \cline { 6 - 7 } & Cluster I & Cluster II & & Cluster I & Cluster II \\
\hline Males & $62.5 \%$ & $37.5 \%$ & & $59.0 \%$ & $41.0 \%$ \\
Females & $5.0 \%$ & $95.0 \%$ & & $19.0 \%$ & $81.0 \%$ \\
\hline
\end{tabular}

in Bulgaria. Therefore, finding working discriminant keys to the sexual dimorphism in this species is a priority task.

Principal component analysis with standardization and varimax rotations, based on correlation matrices was applied. The results for the first two principal components (called futrher PC1 and PC2) based on both absolute and relative cranial measures showed that PC1 explains $42.7 \%$ of the total variance in the data space, while PC2 - only $9.9 \%$. Both principal components could strongly be related to sex (see Fig. 1a). The first PC was related mainly to 43 absolute and 13 relative variables, predominantly lengths, while PC2 was explained by the brain volume (V56) and it's indices, the sizes of $\mathrm{P}^{4}$, and three cranial widths. It is worth mentioning that specimens deviating from their groups on Fig. 1a are practically

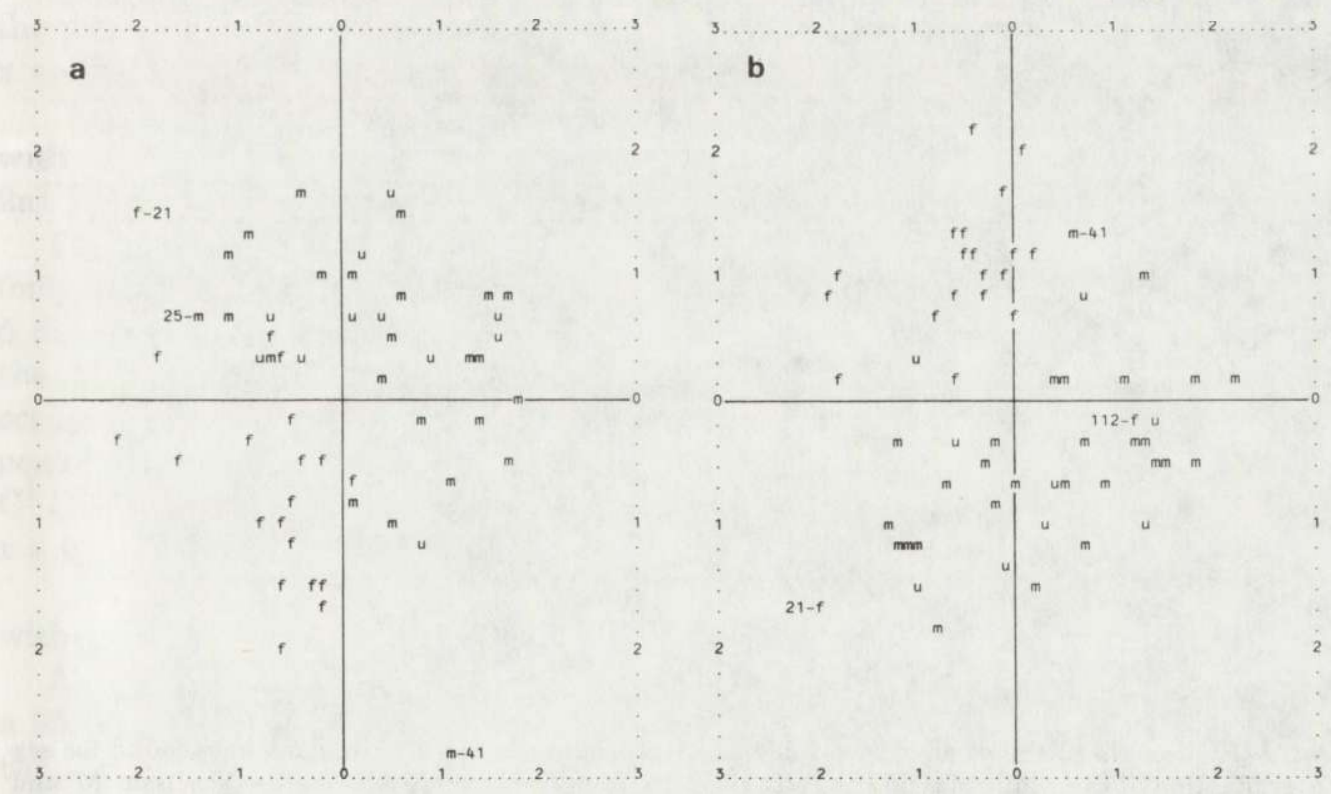

Fig. 1. Individual values of specimens of Felis silvestris from Bulgaria for the $\mathrm{PC} 1$ and $\mathrm{PC} 2$, based both on absolute and relative cranial measurements (a), and mandibular measurements (b). Factor scores is along the abscissa (factor 1) and the ordinate (factor 2). Males are denoted by ' $m$ ', females by ' $\mathrm{f}$ ', and specimens of unknown sexes by ' $\mathrm{u}$ '. Numbers of highly deviating individuals are also given. 
a

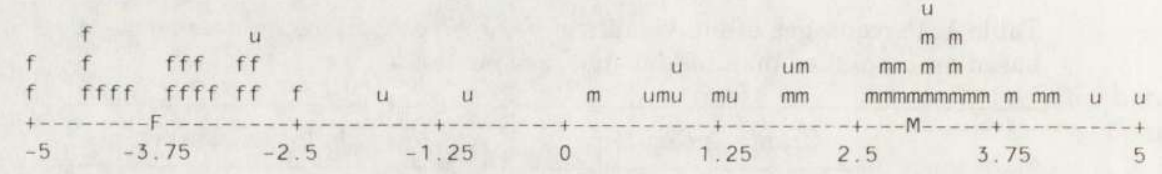

b

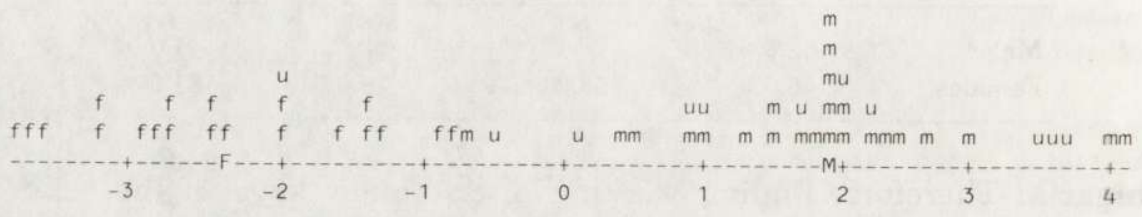

C

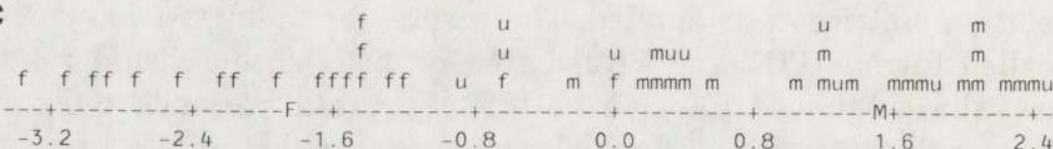

d

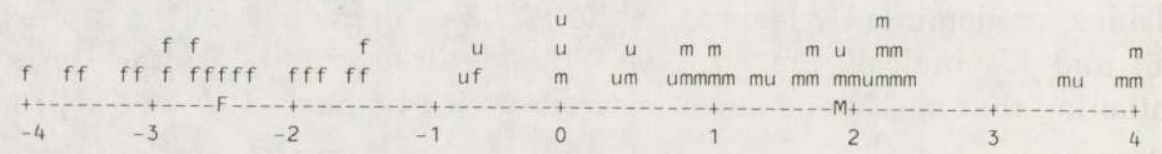

e

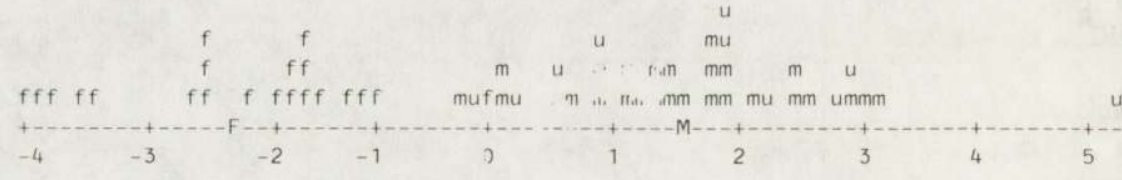

f

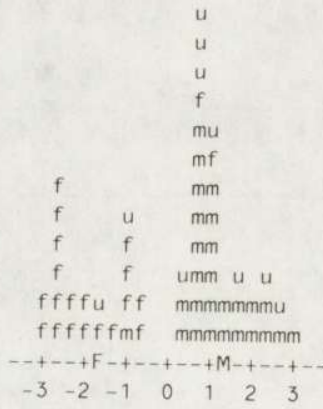

Fig. 2. Histograms of the canonical variable $\mathrm{X}$ corresponding to the discriminant keys found for sex determination of the skulls of wild cat Felis silvestris from Bulgaria. $\mathrm{X}$ is along the abscissa. 'M' and ' $F$ ' stand for the arithmetical means, while ' $m$ ', ' $\mathrm{f}$ ' and ' $u$ ' denote the values for male, female or undetermined individuals. a - first key, based on 9 dimensions of the cranium, b - second key, based on 6 dimensions of the cranium, $\mathrm{c}$ - third key, based on 4 dimensions of the cranium, $\mathrm{d}-$ fourth key, based on 3 absolute and 2 relative dimensions of the cranium, e - fifth key, based on 4 absolute and 2 relative dimensions of the mandible, $\mathrm{f}-$ sixth key, based on the length of $\mathrm{C}_{1}$ (V111). 
the same specimens which were wrongly classified through some discriminant keys, based on the crania (numbers 21,25 , and 41 ), which confirms the explanation of both components by sex.

The PC1 obtained on the basis of both absolute and relative sizes of mandibles explains $49.3 \%$, and the $\mathrm{PC} 2-18.7 \%$ of the total variance in the data space. Both principal components could too much be related to sex (see Fig. 1b). PC1 was more related to common lengths and then to widths, heights, or their indices, while the PC2 - only to teeth sizes and their indices. Once again the same specimens which were wrongly classified through the discriminant keys based on mandible measures (numbers 21, 41, and 112; Fig. 1b), deviated from their groups, which confirms the explanation of both PC's by sex. The results of the PCA demonstrated the sexual dimorphism being the main source of variability in the craniometrical data for the wild cat from Bulgaria.

By means of stepwise discriminant analysis, several classification functions were found. The first key provided a $100 \%$ correct classification and was based on 9 dimensions of each skull: the greatest diameter of the orbit (V14), the distance between processus zygomaticus and crista sagittalis externa posterior (V15), the greatest mastoid breadth (V35), the frontal breadth (V41), the least distance between the meata acustica externa (V42), the least distance between the auditory bulla (V43), height of the foramen magnum (V57), the distance between foramina incisiva (V61) and the least diameter of $\mathrm{C}^{1}$ (V79). In terms of a standardized (by the pooled within-group variances) canonical variable $x$, the key was as follows: $x=-0.8904 \times \mathrm{V} 14+0.8389 \times \mathrm{V} 15+1.3689 \times \mathrm{V} 35-0.601 \times \mathrm{V} 41-0.4641 \times \mathrm{V} 42$$$
-0.7711 \times \mathrm{V} 43+0.836 \times \mathrm{V} 57+1.2921 \times \mathrm{V} 61+2.41518 \times \mathrm{V} 79-53.23661
$$

with the means of 3.04677 and -3.65612 for males and females, respectively, (Fig. 2a).

The second discriminant key presented, provided a $97.7 \%$ correct classification (only the male No 25. was determined wrongly as a female) and it was based on 6 dimensions of each skull: the cranial breadth behind cheek-bone arcks (V33), the distance between proc. zygomaticus and os zygomaticum (V40), the prot. occipitalis height (V52), the distance between os incisivum anterior and os frontale posterior (V66), the height of nasal opening (V69), and the greatest diameter of $\mathrm{C}^{1}$ (V78). In terms of a standardized canonical variable $x$, the key was as follows: $x=0.66418 \times \mathrm{V} 33+0.34561 \times \mathrm{V} 40+0.44966 \times \mathrm{V} 52-0.21997 \times \mathrm{V} 66+0.62691$ $\times \mathrm{V} 69+2.303 \times \mathrm{V} 78-39.38011$

with means of 1.92698 for males and -2.31237 for females (Fig. 2b).

A third discriminant key was produced, basing only on 4 variables. It provided a $95.5 \%$ correct classification, since a male, No. 41 and a female, No. 21 were in the intersection zone of the two "normal" curves (Fig. 2c), being somewhat closer to the center of the opposite group. Nevertheless, the key is useful for its simplicity, since it involves only the distance between the hind edges of osa palatina (V32), the length of the auditory bulla (V45), the height of $\mathrm{C}^{1}$ (V80), and the breadth of $\mathrm{P}^{4}$ (V88). The third key was as follows: 
$x=-0.31303 \times \mathrm{V} 32+0.55335 \times \mathrm{V} 45+0.81814 \times \mathrm{V} 80+1.91179 \times \mathrm{V} 88-23.33241$ with means of 1.53228 for males and -1.83874 for females (Fig. 2c).

In attempt to improve the discrimination between sexes, 32 relative indices were constructed by dividing some variables describing widths, heights or teeth sizes by other ones, mainly skull lengths. On the basis of both absolute and relative sizes a fourth key was obtained, providing a $100 \%$ correct classification. It involves the condylobasal length (V2), the distance between processus zygomaticus and crista sagittalis externa posterior (V15), the least breadth of the supraorbital processes (V31), the cranial breadth behind cheek-bone arcks (V33), the palatal breadth measured between alveoli $\mathrm{C}^{1}$ (V38), the distance between foramina incisiva (V61), and the least diameter of $\mathrm{C}^{1}$ (V79). The fourth discriminant key was as follows:

$x=0.45036 \times \mathrm{V} 15+0.73329 \times \mathrm{V} 33-1.26831 \times \mathrm{V} 38+96.31937 \times \mathrm{V} 61 / \mathrm{V} 2+60.89773$

$\times \mathrm{V} 79 / \mathrm{V} 31-48.19314$

with means of 1.97845 for males and -2.37413 for females (Fig. 2d).

As sometimes in practice only mandibles and not entire skulls are available, discriminant keys based on 32 mandible measurements, and on 17 indices formed out of them, were also produced. Thus, the fifth key provided a $95.8 \%$ correct classification (the male No. 35 and the female No. 112 were closer to the center of the opposite group). It is based on 8 mandible sizes: the mandibular length (V90), the mandibular length (V92), the total length of the mandibular teeth row (V96), the height of corpus mandibulae (V102), the mandibular breadth after $\mathrm{C}_{1}$ (V105), the distance between processus coronoidei (V107), the greatest gauge of corpus mandibulae (V120), and the total length of $\mathrm{C}_{1}$ (V121). The fifth (mandibular) key was as follows:

$x=-0.80739 \times \mathrm{V} 102+0.80112 \times \mathrm{V} 105+1.53886 \times \mathrm{V} 120+0.7158 \times \mathrm{V} 121+$

$+23.42722 \times \mathrm{V} 90 / \mathrm{V} 92+15.34642 \times \mathrm{V} 96 / \mathrm{V} 107-61.32274$

with means of 1.64593 for males and -2.11619 for females (Fig. 2e).

A very simple sixth key based only on one measurement, namely the greatest diameter of $\mathrm{C}_{1}$ (V111), was found. It provided a $93.8 \%$ correct classification (a male, No. 41 and two females: No. 21, and No. 112 were attached to the opposite sex, Fig. 2f). The key is as follows:

$$
x=3.3661 \times \mathrm{V} 111-16.0521
$$

with means of 1.27709 for males and -1.64198 for females (Fig. 2f).

The six keys above show a very high statistical significance $(p<0.0005)$.

\section{Discussion}

Univariate statistics for all the variables used here were presented, together with the results of a $t$-test between the corresponding values for male and female wild cats (Petrov et al. 1990). Univariate analysis showed the means for males being significantly higher than the corresponding values for females in most of 
the measurements taken. However, the results from cluster analysis of cases in this study showed the importance of the outliers in the data, also demonstrated for some other Carnivora species (Buchalczyk and Ruprecht 1977, Reig 1989).

Both cluster analysis and principal component analysis showed sexual differences appearing as the main sources of variability. Sexual dimorphism was related both with dimensions (i.e. absolute sizes) and shapes (relative sizes) of skulls. Among the first ones, more important were lengths, followed by widths, heights, and teeth sizes while among the latter ones - the indices formed by dividing widths to lengths, or brain volumes to lengths differentiate sexes better than those that heights participate in. Similar results with respect of the importance of lengths, widths, heights, as well as their indices, were also obtained for the mandibles. Studies of other species of Carnivora have shown size to be more important in terms of sexual dimorphism for stone marten Martes foina (De Marinis et al. 1990), and shape - for otter Lutra lutra and European badger Meles meles (Wiig 1986).

An important practical advantage of the stepwise discriminant analysis is that it provides keys involving only few dimensions (from 1 to 9 in our case). However, neither the factors responsible for the variability in the data-set could be determined, nor the significance for the sexual dimorphism of all the dimensions used in the analysis, could be estimated. For these purposes a principal component analysis based both on absolute and relative sizes, was performed.

The results of the stepwise discriminant analysis show highly significant differentiation between sexes, and also permit specimens of unknown sex to be classified.

\section{References}

Arrighi J. and Salotti M. 1988. Le chat sauvage (Felis silvestris Schreber, 1777) en Corse. Confirmation de la presence et approche taxonomique. Mammalia 52: 123 - 125.

Buchalczyk T. and Ruprecht A. L. 1977. Skull variability of Mustela putorius Linnaeus, 1758. Acta theriol. 22: $87-120$.

De Marinis A. M., Nikolov' H. and Gerasimov S. 1990. On the sexual dimorphism of stone marten Martes foina Erxl. (Carnivora: Mustelidae) in Italy. Hystrix 2: $35-46$.

Dixon W. J. (ed.) 1981. - BMDP Statistical Software. University of California Press, Berkeley, Los Angeles: $1-727$.

French D. D., Corbet L. K. and Easterbee V. 1988. Morphological discriminants of Scottish wildcats (Felis silvestris), domestic cats (F. catus) and their hybrids. J. Zool., Lond. 214: $235-259$.

Gerasimov S. 1985. Species and sex determination of Martes martes and Martes foina by use of systems of craniometrical indices developed by stepwise discriminant analysis. Mammalia 49: $235-248$.

Petrov I., Gerasimov S. and Nikolov H. 1990. Metric characteristics and sexual dimorphism of cranial features of wild cat (Felis silvestris Schreber, 1777: Mammalia, Felidae) in Bulgaria. Acta zool. bulgarica 40: $44-55$.

Petrov I., Nikolov H. and Gerasimov S. 1992. Craniometrical characteristics and sexual dimorphism of domestic cat (Felis catus L. 1758) in Bulgaria. Acta zool. bulgarica 45: $36-45$.

Reig S. 1989. Errors and misjudgements of outliers in morphometric studies. Fifth Intern. Ther. Congress, Rome, Abstracts of papers and posters, vol. 2: $909-910$. 
Schauenberg P., 1969. L'identification du Chat forestier d'Europe Felis s. silvestris Schreber, 1777 par une methode osteometrique. Rev. suisse zool. 76: $433-441$.

Wetzel M.-C., Solignac M. and Lefebvre J. 1982. Application des analyses multidimensionnelles a l'etude du dimorphisme sexuel des chats harets des iles Kerguelen, en comparison avec une population de chats domestiques du canton de Berne. Mammalia 46: 85 - 100.

Wiig O. 1986. Sexual dimorphism in the skull of minks Mustela vison, badgers Meles meles and otters Lutra lutra. Zool. J. Linn. Soc. 87: 163 - 179.

Received 15 December 1989, revised 25 September 1992, accepted 30 October 1992. 
APPENDIX 1. List of cranial and mandibular measurements of wild cat Felis silvestris from Bulgaria, taken according the scheme illustrated in Fig. 1 (after Petrov et al. 1990).

\begin{tabular}{|c|c|c|c|c|}
\hline \multirow[t]{2}{*}{$\begin{array}{l}\text { Var. } \\
\text { No. }\end{array}$} & \multirow[t]{2}{*}{ Measurements } & \multirow[t]{2}{*}{$\begin{array}{l}\text { Fig. } \\
\text { No. }\end{array}$} & \multicolumn{2}{|c|}{$\begin{array}{c}\text { Measurement } \\
\text { points }\end{array}$} \\
\hline & & & from & to \\
\hline \multirow[t]{2}{*}{1} & 2 & 3 & 4 & \\
\hline & Cranium & & & \\
\hline \multicolumn{2}{|c|}{ 1. Total length } & 3 & 1 & 27 \\
\hline \multicolumn{2}{|c|}{ 2. Condylobasal length } & 2 & 1 & 34 \\
\hline \multicolumn{2}{|c|}{ 3. Basal length } & 2 & 1 & 29 \\
\hline \multicolumn{2}{|c|}{ 4. Neurocranium length } & 3 & 25 & 28 \\
\hline \multicolumn{2}{|c|}{ 5. Basal neurocranium length } & 2 & 2 & 29 \\
\hline \multicolumn{2}{|r|}{ 6. Distance between os incisivum anterior and os palatinum posterior } & 2 & 1 & \\
\hline \multicolumn{2}{|r|}{ 7. Soft palatal length } & 2 & 2 & \\
\hline \multicolumn{2}{|c|}{ 8. Profile length } & 3 & 1 & 28 \\
\hline \multicolumn{2}{|c|}{ 9. Facial length } & 1 & 1 & 25 \\
\hline \multicolumn{2}{|r|}{ 11. Lateral length of snout oral border of the orbit } & 3 & 1 & 36 \\
\hline \multirow{2}{*}{\multicolumn{2}{|c|}{$\begin{array}{l}\text { 12. Frontal length (between anterior edge alveolus } \mathrm{I}^{1} \text { and proc. zygomaticus) } \\
\text { 13. Distance between foramen infraorbitale and crista sagittalis }\end{array}$}} & 3 & 1 & \\
\hline & & \multicolumn{2}{|c|}{ externa posterior } & 27 \\
\hline \multicolumn{5}{|c|}{ 14. Greatest diameter of the orbit } \\
\hline \multicolumn{2}{|r|}{$\begin{array}{l}\text { 15. Distance between proc. zygomaticus and crista sagittalis } \\
\text { externa posterior }\end{array}$} & 1 & 8 & 27 \\
\hline \multicolumn{2}{|c|}{ 16. Basifacial axis } & 3 & 1 & 3 \\
\hline \multicolumn{2}{|c|}{ 17. Check-bone length } & 2 & 5 & 13 \\
\hline \multicolumn{2}{|c|}{ 18. Crista occipitalis length } & 3 & 27 & 47 \\
\hline \multicolumn{2}{|c|}{ 19. Crista sagittalis length } & 1 & 26 & 27 \\
\hline \multicolumn{2}{|c|}{ 20. Greatest length of the nasal bone } & 1 & 51 & 25 \\
\hline \multicolumn{2}{|r|}{$\begin{array}{l}\text { 21. Palatal length: the medial point of inter-section of the line joining } \\
\text { the deepest indentations of the Choanae - Prosthion }\end{array}$} & 2 & 1 & 38 \\
\hline \multicolumn{2}{|r|}{ 22. Length of the lamina horizontalis ossis palatini } & 2 & 38 & 39 \\
\hline \multicolumn{2}{|c|}{ 23. Length of the os maxillare } & 1 & 1 & 40 \\
\hline 24. D & $\begin{array}{l}\text { Distance between os frontale posterior and crista sagittalis } \\
\text { externa anterior }\end{array}$ & 1 & 50 & 26 \\
\hline 25. 0 & Os nasale length & 1 & 24 & 25 \\
\hline 26. $\mathrm{R}$ & Rostrum breadth: measured across outer borders at the canine alveoli & 1 & 7 & 7 \\
\hline 27. $\mathrm{F}$ & Facial breadth (between the infraorbital foramina - least distance) & 4 & 5 & \\
\hline 28. $\mathrm{D}$ & Distance between eye-orbits (external) & 1 & 44 & 44 \\
\hline 29. $\mathrm{Z}$ & Zygomatic breadth (greatest) & 1 & 9 & 9 \\
\hline 30. L & Least breadth between the orbits & 1 & 35 & 35 \\
\hline 31. L & Least breadth aboral of the supraorbital processes & 1 & 12 & 12 \\
\hline 32. D & Distance between the hind edges of osa palatina & 2 & 31 & 31 \\
\hline 33. $\mathrm{C}$ & Cranial breadth behind cheek-bone arcks & 2 & 13 & 13 \\
\hline 34. G & Greatest breadth of braincase & 1 & 14 & 14 \\
\hline 35. G & Greatest mastoid breadth & 1 & 15 & 15 \\
\hline 36. D & Distance between upper-jaw joints (external) & 2 & 32 & 32 \\
\hline
\end{tabular}



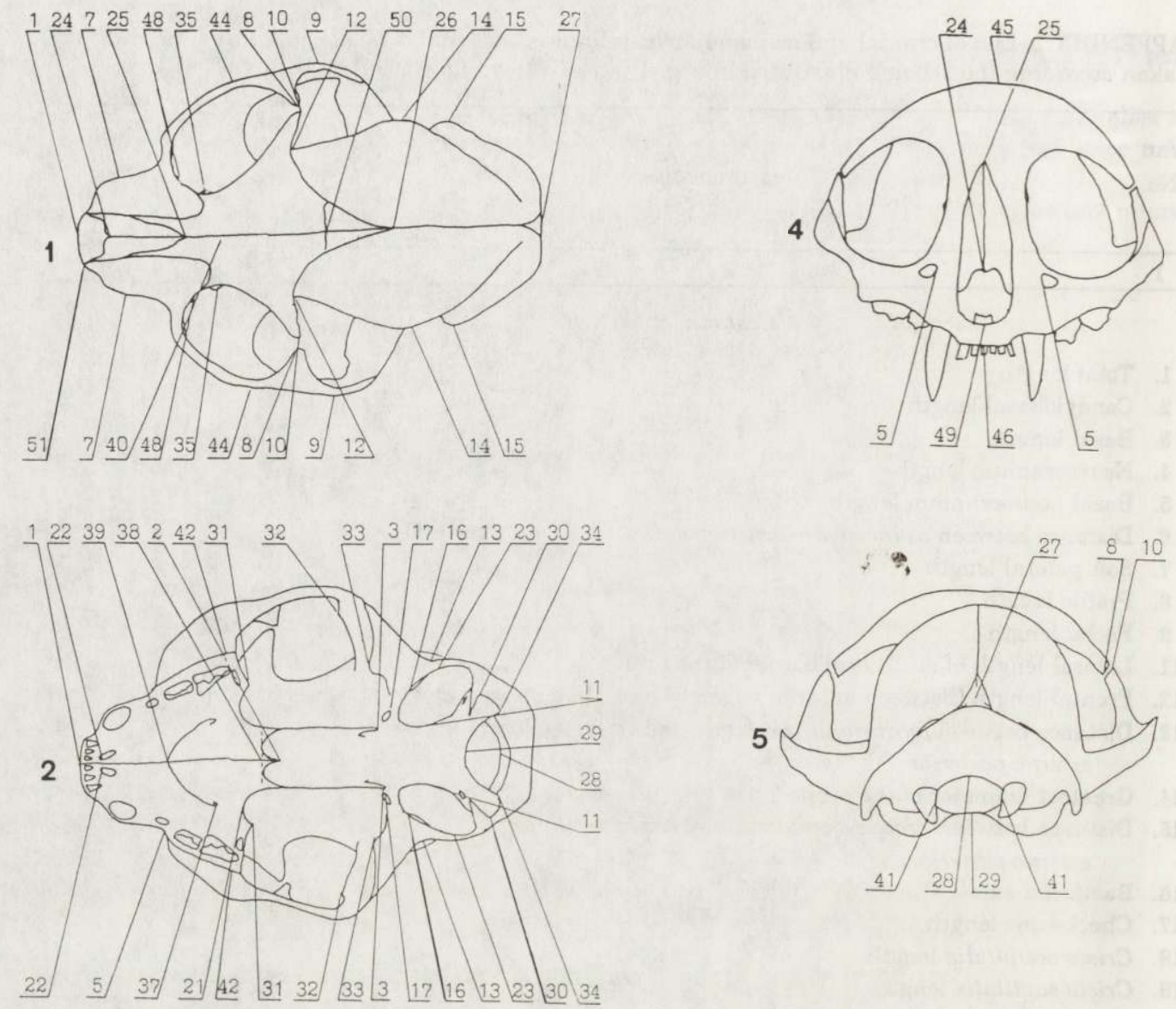

$22 \sqrt[5]{37} \quad 21 \quad 42 \quad \begin{array}{lllllllllll}31 & 32 & 33 & 3 & 17 & 16 & 13 & 23 & 30 & 34\end{array}$
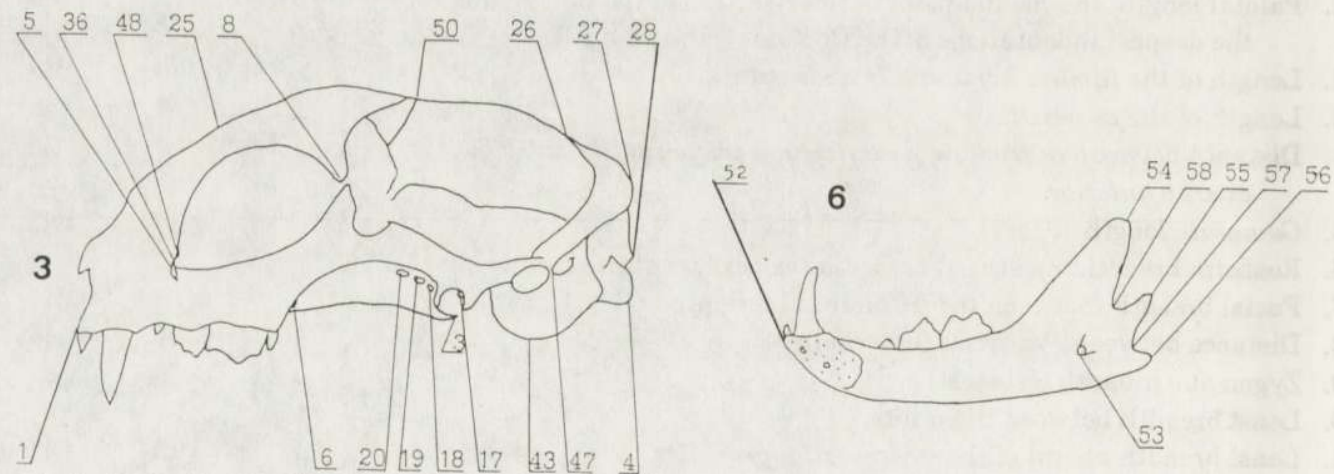

Appendix 1. Figs $1-6$. Scheme of the wild cats' Felis silvestris skull showing the location of measuring points (after Petrov et al. 1990).

1 - dorsal view, 2 - ventral view, 3 - lateral view, 4 - frontal view,

5 - posterior view of the skull, 6 - lateral lingual view of the mandible. 
APPENDIX 1 - continued.

\begin{tabular}{lccr}
\hline \multicolumn{1}{c}{2} & 3 & 4 & 5 \\
\hline 37. Distance between upper-jaw joints (internal) & 2 & 33 & 33 \\
38. Palatal breadth: measured between alveoli $C^{1}$ (internal) & & not shown \\
39. Greatest palatal breadth: measured across the borders of the alveoli & 2 & 42 & 42 \\
$\quad M^{1}$ (internal) & & & \\
40. Distance between processus zygomaticus and os zygomaticum & 1 & 8 & 8 \\
41. Frontal breadth & 1 & 16 & 16 \\
42. Distance between the meata acustica externa (least) & 2 & 11 & 11 \\
43. Least distance between the auditory bullae & 2 & 23 & 23 \\
44. Breadth measured across the outer borders at the auditory bullae & 2 & not shown \\
45. Length of the auditory bulla: from the most aborolateral points to the & & &
\end{tabular}

46. Least diameter of the auditory bulla: from the middle of the opening of the external acoustic meatus up to the most medial protrusion of the bulla on the opposite side of the bulla

47. Breadth of processus pterygoideus

48. Greatest breadth of the occipital condyles

49. Facial height: measured through the hind end of os nasale

50. Greatest height of the cranium

51. Cranial height: measured through the auditory bulla

52. Height of the protuberantia occipitalis

54. Height of os incisivum at alveoli incisiva

55. Rear height

56. Neurocranium capacity

57. Height of the foramen magnum

58. Breadth of the foramen magnum

59. Greatest diameter of the meatus acusticus externus

60. Least diameter of the meatus acusticus externus

61. Distance between foramina incisiva

62. Distance between foramen ovale and foramen rotundum

63. Distance between foramen ovale and fissa orbitalis

64. Distance between foramen ovale and foramen opticum

65. Distance between foramina ovalia

66. Distance between os incisivum anterior and os frontale posterior

67. Least diameter of the orbit

68. Breadth of the nasal opening: measured between osa incisiva

69. Height of the nasal opening: measured between os incisivum and os nasale

70. Distance between lacrimal ducts (canalis lacrimalis)

71. Distance between os incisivum anterior and crista sagittalis externa anterior

72. Distance between os nasale posterior and crista sagittalis externa posterior

73. Distance between foramen sphenopalatinum and canalis lacrimalis

74. Distance from the arch of os palatinum to canalis palatinus

not shown

$30 \quad 30$

$25 \quad \mathrm{~h}$

$45 \quad \mathrm{~h}$

$26 \quad 43$

$27 \quad 28$

$46 \quad 49$

$26 \quad 4$

not shown

$28 \quad 29$

$41 \quad 41$

not shown

not shown

$22 \quad 22$

$17 \quad 18$

$17 \quad 19$

$17 \quad 20$

$17 \quad 17$

150

not shown

not shown

$24 \quad 49$

$48 \quad 48$

126

$25 \quad 27$

$6 \quad 48$

$21 \quad 37$ 
APPENDIX 1 - continued.

\begin{tabular}{llllll}
\hline 1 & 2 & 3 & 4 & 5 \\
\hline
\end{tabular}

75. Length of maxilar teeth row from the fore end of alveolus $\mathrm{I}^{1}$

not shown to the hind end of alveolus $\mathrm{M}^{1}$

76. Length of incisive teeth row

77. Distance between alveolus $\mathrm{I}^{3}$ and alveolus $\mathrm{C}^{1}$

78. Greatest diameter of $\mathrm{C}^{1}$ : measured near to the alveolus

79. Least diameter of $\mathrm{C}^{1}$ : measured near the alveolus

80. Height of the $C^{1}$ : measured above the alveolus

82. Distance between posterior edge of alveolus $\mathrm{C}^{1}$ and anterior edge of alveolus $\mathrm{P}^{3}$

83. Length of the cheektooth row: measured on the buccal side

84. Teeth row length: measured between posterior edge of alveolus $\mathrm{C}^{1}$ and posterior edge of alveola $\mathrm{M}^{1}$

85. Length of the premolar row: measured along the alveoli on the buccal side

86. Length of premolar row on $\mathrm{P}^{3}$ and $\mathrm{P}^{4}$

87. Length of $\mathrm{P}^{4}$ : measured on the buccal side

88. Breadth of $\mathrm{P}^{4}$

89. Distance between the tips of $\mathrm{C}^{1}$

\section{Mandible}

90. Length of the mandible: measured between anterior edge of alveolus $\mathrm{I}_{1}$ and processus coronoideus posterior

91. Length of the mandible: measured between anterior edge of alveolus $I_{1}$ and the middle of processus condyloideus

92. Length of the mandible: measured between anterior edge of alveolus $I_{1}$ and processus angularis posterior

93. Length of processus condyloideus

94. Distance between processus condyloidei

95. Height of the ramus mandibulae

96. Total length of the mandible teeth row

97. Distance between anterior edge of alveolus $\mathrm{I}_{1}$ and incisura mandibulare

98. Distance from anterior edge of alveolus $I_{1}$ to the angle between processus condyloideus and processus angularis

99. Distance between posterior egde of alveolus $\mathrm{C}_{1}$ to processus coronoideus

100. Distance between posterior egde of alveolus $C_{1}$ and the angle between processus condyloideus and processus angularis

101. Distance between posterior egde of alveolus $C_{1}$ and processus angularis

102. Height of corpus mandibulae measured in the point between $\mathrm{P}_{3}$ and $\mathrm{P}_{4}$

103. Height of corpus mandibulae measured behind $\mathrm{M}_{1}$

104. Total height of corpus mandibulae

105 Mandibular breadth after $\mathrm{C}_{1}$

106. Distance between the middles of alveolus $\mathrm{C}_{1}$ (internal)

107. Distance between processus coronoidei

108. Distance between processus angularies

not shown

not shown

not shown

not shown

not shown

not shown

$\begin{array}{lll}2 & \mathrm{P}^{2} & \mathrm{M}^{1}\end{array}$

$2 \quad \mathrm{C}^{1} \quad \mathrm{M}^{1}$

$2 \quad \mathrm{P}^{2} \quad \mathrm{P}^{4}$

$2 \quad$ P3 $\quad \mathrm{P}^{4}$

not shown

not shown

not shown

$\begin{array}{lll}6 & 52 & 54\end{array}$

$6 \quad 52$

55

$\begin{array}{lll}6 & 52 & 56\end{array}$

not shown

not shown

$54 \quad 55$

$\mathrm{I}_{1} \quad \mathrm{M}_{1}$

$\begin{array}{lll}6 & 52 & 58 \\ 6 & 52 & 57\end{array}$

$\begin{array}{llll}6 & \mathrm{C}_{1} & 54\end{array}$

$\begin{array}{llll}6 & \mathrm{C}_{1} & 57\end{array}$

$\begin{array}{llll}6 & \mathrm{C}_{1} & 56\end{array}$

not shown

not shown

$54 \quad 56$

not shown

not shown

not shown

not shown 
APPENDIX 1 - concluded.

\begin{tabular}{lccc}
\hline \multicolumn{1}{c}{2} & 3 & 4 & 5 \\
\hline 1 & 6 & 52 & 53 \\
109. Distance between anterior edge of alveolus $\mathrm{I}_{1}$ to foramen mandibulare & 6 & 56 \\
110. Distance between foramen mandibulare and processus angularis & 6 & 53 & not shown \\
111. Greatest diameter of $\mathrm{C}_{1}$ measured near to the alveolus & & $\mathrm{C}_{1}$ & $\mathrm{M}_{1}$ \\
112. Distance from posterior edge of $\mathrm{C}_{1}$ to posterior edge of $\mathrm{M}_{1}$ & 6 & $\mathrm{P}_{3}$ & $\mathrm{M}_{1}$ \\
113. Length of cheektooth row: measured between anterior edge of $\mathrm{P}_{3}$ & 6 & & \\
$\quad$ posterior edge of $\mathrm{M}_{1}$ & 6 & $\mathrm{P}_{3}$ & $\mathrm{P}_{4}$ \\
114. Length of premolar row & & not shown \\
115. Length of $\mathrm{M}_{1}$ & & not shown \\
116. Greatest breadth of $\mathrm{M}_{1}$ & & not shown \\
117. Distance between the tips of $\mathrm{C}_{1}$ & & not shown \\
118. Breadth of $\mathrm{C}_{1}$ measured near alveolus & & not shown \\
119. Height of $\mathrm{C}_{1}$ measured above the alveolus & & not shown \\
120. Greatest gauge of corpus mandibulae & not shn \\
121. Total length of the $\mathrm{C}_{1}$ & &
\end{tabular}


APPENDIX 2. Arithmetic means and standard deviations of 118 craniometrical measurements of wild cat Felis silvestris from Bulgaria (numeration and description of the measurements after Petrov et al. 1990, except V10, V53, V81).

\begin{tabular}{|c|c|c|c|c|c|c|c|c|c|}
\hline \multirow[b]{2}{*}{ V } & \multicolumn{4}{|c|}{ Males } & \multicolumn{4}{|c|}{ Females } & \multirow{2}{*}{$t$} \\
\hline & $\bar{x}$ & SD & $\min$ & $\max$ & $\bar{x}$ & SD & $\min$ & $\max$ & \\
\hline \multirow[t]{2}{*}{1} & 2 & 3 & 4 & 5 & 6 & 7 & 8 & 9 & 10 \\
\hline & & Cranium & & & & & & & \\
\hline 1 & 98.86 & 4.84 & 89.1 & 105.3 & 91.85 & 3.42 & 84.4 & 97.3 & 5.44 \\
\hline 2 & 91.04 & 4.11 & 83.5 & 96.4 & 84.95 & 3.04 & 78.6 & 89.5 & 5.49 \\
\hline 3 & 83.88 & 4.28 & 72.3 & 89.0 & 78.28 & 2.74 & 71.4 & 82.5 & 5.05 \\
\hline 4 & 74.75 & 3.12 & 67.8 & 78.4 & 70.57 & 2.66 & 65.0 & 74.0 & 4.73 \\
\hline 5 & 44.34 & 2.36 & 40.2 & 48.0 & 41.19 & 2.02 & 37.3 & 44.7 & 4.70 \\
\hline 6 & 39.79 & 2.14 & 35.5 & 43.7 & 36.99 & 1.31 & 34.4 & 38.9 & 5.08 \\
\hline 7 & 18.70 & 1.50 & 16.5 & 21.3 & 17.91 & 1.42 & 15.0 & 20.1 & 1.78 \\
\hline 8 & 93.70 & 4.27 & 85.3 & 99.3 & 87.83 & 3.10 & 81.2 & 92.6 & 5.12 \\
\hline 9 & 38.22 & 2.18 & 34.0 & 42.5 & 35.72 & 1.63 & 33.4 & 39.7 & 4.23 \\
\hline 11 & 26.66 & 1.52 & 24.1 & 28.8 & 24.66 & 1.19 & 22.0 & 26.4 & 4.78 \\
\hline 12 & 55.31 & 2.82 & 50.0 & 58.8 & 52.41 & 2.26 & 48.1 & 55.5 & 3.71 \\
\hline 13 & 81.38 & 3.86 & 73.0 & 87.3 & 75.74 & 2.67 & 70.0 & 80.1 & 5.52 \\
\hline 14 & 28.66 & 1.39 & 26.1 & 30.5 & 27.87 & 0.99 & 26.0 & 29.4 & 2.13 \\
\hline 15 & 60.63 & 3.20 & 54.7 & 66.0 & 56.09 & 2.37 & 50.9 & 59.4 & 5.25 \\
\hline 16 & 57.20 & 3.01 & 52.2 & 62.4 & 53.76 & 2.11 & 49.4 & 56.1 & 4.30 \\
\hline 17 & 52.64 & 2.65 & 46.0 & 56.2 & 49.08 & 2.20 & 45.1 & 51.8 & 4.77 \\
\hline 18 & 35.58 & 1.73 & 32.9 & 38.1 & 33.14 & 1.05 & 31.0 & 34.7 & 5.50 \\
\hline 19 & 19.13 & 6.51 & 8.0 & 34.0 & 13.73 & 2.73 & 8.0 & 17.5 & 3.46 \\
\hline 20 & 27.57 & 1.73 & 24.9 & 30.7 & 25.98 & 1.52 & 23.4 & 29.5 & 3.21 \\
\hline 21 & 38.07 & 1.94 & 34.3 & 41.0 & 35.32 & 1.28 & 32.7 & 37.1 & 5.43 \\
\hline 22 & 16.34 & 1.08 & 14.4 & 17.8 & 14.79 & 0.96 & 12.3 & 16.5 & 5.01 \\
\hline 23 & 36.02 & 1.86 & 31.7 & 39.1 & 33.12 & 1.41 & 30.8 & 35.5 & 5.73 \\
\hline 24 & 27.43 & 4.32 & 18.1 & 37.0 & 28.62 & 1.71 & 25.5 & 31.7 & -1.16 \\
\hline 25 & 23.72 & 2.17 & 20.3 & 28.9 & 22.22 & 1.41 & 19.4 & 25.6 & 2.66 \\
\hline 26 & 25.28 & 1.53 & 22.1 & 27.9 & 23.32 & 0.94 & 21.8 & 24.7 & 4.99 \\
\hline 27 & 27.74 & 1.83 & 24.9 & 31.2 & 25.97 & 1.22 & 23.6 & 27.7 & 3.69 \\
\hline 28 & 62.30 & 3.42 & 57.6 & 68.7 & 59.92 & 2.44 & 54.3 & 63.4 & 2.61 \\
\hline 29 & 70.46 & 4.90 & 62.2 & 79.2 & 65.22 & 3.23 & 58.2 & 70.3 & 4.09 \\
\hline 30 & 19.20 & 1.44 & 17.2 & 23.1 & 18.14 & 1.07 & 16.0 & 19.8 & 2.72 \\
\hline 31 & 33.76 & 1.79 & 30.0 & 37.2 & 34.03 & 1.21 & 32.0 & 36.7 & 0.57 \\
\hline 32 & 30.68 & 2.14 & 27.1 & 36.0 & 29.60 & 1.91 & 25.5 & 32.4 & 1.75 \\
\hline 33 & 42.07 & 1.28 & 39.5 & 44.4 & 39.73 & 0.80 & 38.3 & 41.0 & 7.09 \\
\hline 34 & 46.43 & 1.12 & 43.3 & 48.8 & 45.34 & 1.04 & 43.2 & 47.8 & 3.32 \\
\hline 35 & 44.26 & 1.59 & 40.7 & 46.5 & 41.37 & 0.61 & 40.1 & 42.6 & 7.66 \\
\hline 36 & 57.25 & 3.16 & 52.5 & 63.4 & 53.12 & 1.85 & 49.0 & 56.2 & 5.15 \\
\hline 37 & 34.47 & 1.66 & 32.0 & 37.9 & 32.35 & 1.16 & 30.5 & 34.0 & 4.81 \\
\hline 38 & 14.28 & 1.19 & 12.0 & 16.2 & 13.71 & 1.00 & 11.5 & 15.1 & 1.70 \\
\hline 39 & 35.58 & 1.54 & 32.9 & 38.5 & 34.14 & 1.31 & 32.0 & 36.0 & 3.30 \\
\hline 40 & 2.74 & 1.93 & 0.0 & 5.9 & 2.64 & 1.91 & 0.0 & 6.9 & 0.19 \\
\hline 41 & 51.10 & 4.02 & 44.0 & 57.6 & 49.57 & 2.95 & 43.1 & 54.5 & 1.41 \\
\hline
\end{tabular}


Sexual dimorphism in skull of wild cat

APPENDIX 2 - continued.

\begin{tabular}{|c|c|c|c|c|c|c|c|c|c|}
\hline 1 & 2 & 3 & 4 & 5 & 6 & 7 & 8 & 9 & 10 \\
\hline 42 & 32.97 & 1.93 & 29.3 & 36.3 & 30.83 & 0.98 & 28.7 & 32.8 & 4.49 \\
\hline 43 & 9.82 & 0.67 & 8.9 & 11.7 & 9.31 & 0.68 & 8.1 & 10.5 & 2.50 \\
\hline 44 & 38.37 & 1.50 & 35.5 & 40.9 & 36.38 & 1.22 & 34.7 & 39.0 & 4.76 \\
\hline 45 & 21.47 & 1.30 & 19.5 & 24.0 & 19.85 & 0.72 & 18.0 & 21.5 & 4.95 \\
\hline 46 & 13.64 & 0.62 & 12.1 & 14.6 & 12.85 & 0.48 & 11.9 & 13.6 & 4.65 \\
\hline 47 & 13.82 & 0.81 & 12.5 & 15.4 & 13.43 & 0.77 & 12.1 & 15.3 & 1.63 \\
\hline 48 & 24.30 & 0.85 & 22.6 & 26.0 & 23.34 & 0.69 & 21.8 & 24.5 & 4.06 \\
\hline 49 & 28.81 & 1.44 & 26.2 & 31.3 & 27.29 & 1.32 & 25.0 & 29.7 & 3.62 \\
\hline 50 & 38.59 & 1.09 & 36.9 & 40.8 & 36.96 & 1.05 & 35.3 & 3.89 & 5.02 \\
\hline 51 & 41.10 & 2.45 & 34.4 & 43.9 & 37.98 & 1.31 & 34.2 & 39.7 & 5.11 \\
\hline 52 & 15.85 & 1.18 & 13.5 & 18.0 & 14.52 & 0.99 & 12.3 & 16.7 & 4.00 \\
\hline 54 & 5.32 & 0.65 & 4.0 & 6.6 & 4.64 & 0.48 & 4.0 & 5.8 & 3.93 \\
\hline 55 & 37.22 & 4.43 & 29.0 & 44.7 & 33.62 & 1.95 & 29.3 & 37.5 & 3.37 \\
\hline 56 & 40.25 & 2.45 & 35.0 & 44.5 & 37.64 & 2.33 & 34.0 & 42.6 & 3.60 \\
\hline 57 & 12.79 & 0.95 & 11.1 & 14.9 & 12.68 & 0.75 & 11.3 & 14.5 & 0.42 \\
\hline 58 & 14.99 & 0.65 & 13.8 & 16.6 & 14.93 & 0.48 & 14.0 & 15.6 & 0.32 \\
\hline 59 & 6.95 & 0.32 & 6.0 & 7.4 & 6.96 & 0.27 & 6.6 & 7.6 & -0.10 \\
\hline 60 & 4.38 & 0.20 & 4.0 & 4.7 & 4.28 & 0.17 & 4.0 & 4.6 & 1.55 \\
\hline 61 & 2.30 & 0.41 & 1.3 & 3.5 & 2.01 & 0.44 & 1.4 & 2.8 & 2.26 \\
\hline 62 & 3.38 & 0.68 & 2.2 & 4.9 & 3.10 & 0.50 & 2.6 & 4.3 & 1.53 \\
\hline 63 & 6.21 & 0.65 & 5.0 & 7.7 & 5.95 & 0.45 & 5.0 & 6.6 & 1.57 \\
\hline 64 & 11.18 & 1.05 & 9.6 & 13.5 & 10.67 & 0.65 & 9.2 & 12.0 & 1.85 \\
\hline 65 & 20.85 & 1.17 & 17.8 & 22.3 & 20.14 & 0.67 & 19.1 & 21.4 & 2.40 \\
\hline 66 & 68.15 & 3.75 & 58.0 & 73.0 & 64.74 & 2.16 & 60.9 & 68.5 & 3.60 \\
\hline 67 & 24.78 & 1.10 & 23.0 & 27.0 & 24.03 & 0.91 & 22.3 & 25.3 & 2.28 \\
\hline 68 & 11.99 & 0.88 & 10.5 & 13.9 & 10.75 & 0.85 & 8.8 & 11.8 & 4.76 \\
\hline 69 & 10.69 & 0.90 & 8.6 & 12.0 & 9.97 & 0.54 & 8.8 & 11.0 & 3.13 \\
\hline 70 & 24.94 & 2.18 & 21.5 & 29.0 & 23.16 & 1.42 & 20.2 & 25.4 & 3.14 \\
\hline 71 & 88.12 & 2.84 & 83.5 & 93.4 & 84.68 & 2.54 & 80.0 & 90.2 & 4.20 \\
\hline 72 & 74.87 & 3.50 & 67.1 & 80.0 & 69.86 & 2.94 & 64.4 & 73.2 & 5.08 \\
\hline 73 & 13.48 & 0.87 & 11.7 & 14.9 & 12.28 & 0.55 & 11.0 & 73.2 & 5.08 \\
\hline 74 & 7.90 & 1.09 & 6.4 & 10.7 & 7.74 & 0.76 & 6.6 & 9.6 & 0.59 \\
\hline 75 & 39.13 & 1.60 & 36.0 & 41.4 & 37.08 & 0.94 & 35.0 & 38.5 & 5.04 \\
\hline 76 & 9.93 & 0.54 & 9.1 & 11.0 & 9.59 & 0.48 & 9.0 & 10.9 & 2.12 \\
\hline 77 & 3.92 & 0.73 & 2.5 & 5.1 & 3.72 & 0.51 & 2.5 & 4.7 & 1.01 \\
\hline 78 & 5.90 & 0.53 & 4.7 & 7.2 & 4.89 & 0.27 & 4.5 & 5.4 & 7.66 \\
\hline 79 & 4.25 & 0.32 & 3.5 & 4.8 & 3.62 & 0.20 & 3.3 & 4.0 & 7.64 \\
\hline 80 & 14.27 & 1.36 & 11.5 & 17.2 & 11.73 & 0.83 & 9.6 & 13.6 & 7.22 \\
\hline 82 & 6.38 & 0.92 & 5.0 & 8.7 & 6.00 & 0.92 & 4.3 & 7.4 & 1.36 \\
\hline 83 & 23.10 & 0.95 & 21.4 & 24.8 & 21.93 & 0.87 & 20.5 & 24.3 & 4.19 \\
\hline 84 & 25.39 & 1.09 & 23.1 & 27.3 & 24.50 & 0.97 & 22.5 & 26.5 & 2.85 \\
\hline 85 & 22.40 & 0.66 & 21.0 & 23.7 & 21.28 & 0.75 & 20.0 & 22.7 & 5.27 \\
\hline 86 & 18.72 & 0.60 & 17.4 & 20.0 & 18.10 & 0.59 & 17.0 & 19.0 & 3.44 \\
\hline 87 & 11.45 & 0.44 & 10.7 & 12.7 & 10.99 & 0.57 & 10.1 & 12.2 & 2.95 \\
\hline 88 & 5.72 & 0.34 & 5.0 & 6.4 & 5.30 & 0.22 & 4.9 & 5.6 & 4.75 \\
\hline 89 & 17.61 & 1.62 & 13.7 & 21.0 & 16.25 & 1.08 & 14.8 & 18.6 & 3.18 \\
\hline
\end{tabular}


APPENDIX 2 - concluded.

\begin{tabular}{|c|c|c|c|c|c|c|c|c|c|}
\hline 1 & 2 & 3 & 4 & 5 & 6 & 7 & 8 & 9 & 10 \\
\hline & & Mandib & & & & & & & \\
\hline 90 & 65.92 & 3.97 & 59.40 & 72.3 & 62.18 & 3.62 & 56.0 & 70.4 & 3.36 \\
\hline 91 & 63.24 & 3.58 & 57.0 & 68.5 & 59.58 & 3.02 & 53.4 & 66.8 & 3.76 \\
\hline 92 & 64.56 & 4.55 & 56.5 & 71.7 & 60.68 & 3.59 & 53.1 & 69.5 & 3.21 \\
\hline 93 & 14.43 & 1.73 & 11.3 & 17.5 & 13.56 & 1.42 & 11.0 & 16.6 & 1.87 \\
\hline 94 & 32.86 & 2.07 & 28.2 & 36.4 & 30.81 & 2.99 & 26.3 & 36.3 & 2.81 \\
\hline 95 & 16.57 & 1.96 & 13.2 & 20.8 & 14.56 & 1.55 & 11.4 & 18.6 & 3.85 \\
\hline 96 & 36.61 & 1.40 & 33.7 & 39.0 & 34.66 & 1.22 & 32.3 & 37.9 & 5.06 \\
\hline 97 & 59.30 & 3.42 & 53.0 & 64.5 & 55.77 & 2.86 & 49.9 & 63.0 & 3.80 \\
\hline 98 & 61.89 & 3.56 & 54.6 & 68.0 & 58.15 & 3.10 & 51.8 & 66.5 & 3.92 \\
\hline 99 & 58.04 & 3.77 & 51.5 & 64.2 & 54.77 & 3.43 & 49.0 & 62.9 & 3.10 \\
\hline 100 & 53.72 & 3.57 & 46.2 & 59.5 & 50.91 & 3.02 & 44.5 & 58.1 & 2.89 \\
\hline 101 & 56.51 & 4.29 & 48.7 & 63.5 & 53.59 & 3.39 & 46.5 & 61.5 & 2.55 \\
\hline 102 & 10.80 & 0.99 & 9.0 & 12.4 & 9.98 & 0.90 & 8.5 & 11.9 & 2.96 \\
\hline 103 & 11.86 & 0.72 & 10.5 & 13.1 & 10.89 & 0.91 & 9.4 & 12.7 & 4.38 \\
\hline 104 & 28.16 & 2.87 & 23.5 & 34.0 & 25.79 & 2.20 & 22.0 & 31.7 & 3.13 \\
\hline 105 & 12.85 & 0.75 & 11.7 & 15.0 & 11.70 & 0.58 & 11.0 & 13.1 & 5.80 \\
\hline 106 & 5.79 & 0.54 & 5.0 & 6.8 & 6.05 & 0.63 & 4.5 & 7.2 & -1.55 \\
\hline 107 & 50.49 & 3.53 & 44.4 & 55.5 & 49.44 & 4.15 & 41.2 & 56.7 & 0.95 \\
\hline 108 & 43.32 & 4.40 & 37.0 & 52.3 & 41.41 & 4.03 & 35.5 & 50.0 & 1.56 \\
\hline 109 & 48.67 & 2.58 & 43.0 & 52.6 & 45.61 & 2.34 & 41.0 & 51.9 & 4.24 \\
\hline 110 & 15.71 & 2.92 & 12.0 & 24.3 & 15.02 & 1.49 & 12.4 & 18.2 & 0.99 \\
\hline 111 & 5.15 & 0.25 & 4.5 & 5.7 & 4.28 & 0.35 & 3.9 & 5.1 & 10.05 \\
\hline 112 & 28.45 & 1.02 & 26.1 & 30.0 & 27.49 & 1.60 & 25.5 & 29.9 & 3.03 \\
\hline 113 & 21.85 & 0.94 & 18.3 & 23.0 & 21.10 & 0.73 & 19.5 & 22.6 & 3.01 \\
\hline 114 & 13.76 & 0.49 & 13.0 & 14.7 & 13.12 & 0.50 & 11.8 & 13.9 & 4.45 \\
\hline 115 & 8.84 & 0.43 & 7.7 & 9.5 & 8.35 & 0.37 & 7.7 & 9.0 & 4.24 \\
\hline 116 & 3.58 & 0.22 & 3.2 & 4.1 & 3.53 & 0.26 & 3.0 & 4.2 & 0.58 \\
\hline 117 & 16.87 & 1.23 & 14.6 & 20.0 & 15.59 & 0.78 & 14.0 & 17.3 & 4.16 \\
\hline 118 & 3.81 & 0.27 & 3.2 & 4.3 & 3.21 & 0.29 & 2.8 & 3.9 & 5.79 \\
\hline 119 & 12.44 & 1.60 & 9.9 & 16.9 & 10.78 & 0.99 & 9.0 & 13.3 & 5.17 \\
\hline 120 & 5.97 & 0.56 & 5.0 & 7.3 & 5.28 & 0.16 & 5.0 & 5.6 & 5.46 \\
\hline 121 & 23.99 & 1.05 & 22.0 & 26.3 & 21.02 & 2.23 & 16.7 & 24.3 & 6.12 \\
\hline
\end{tabular}

